\title{
Prediksi Kedatangan Turis Asing ke Indonesia Menggunakan Backpropagation Neural Networks
}

\author{
Haviluddin*), Zainal Arifin, Awang Harsa Kridalaksana, Dedy Cahyadi \\ Fakultas Ilmu Komputer dan Teknologi Informasi, Universitas Mulawarman
}

\begin{abstract}
In this paper, a backpropagation neural network (BPNN) method with time series data have been explored. The BPNN method to predict the foreign tourist's arrival to Indonesia datasets have been implemented. The foreign tourist's arrival datasets were taken from the center agency on statistics (BPS) Indonesia. The experimental results showed that the BPNN method with two hidden layers were able to forecast foreign tourist's arrival to Indonesia. Where, the mean square error (MSE) as forecasting accuracy has been indicated. In this study, the BPNN method is able and recommended to be alternative methods for predicting time series datasets. Also, the BPNN method showed that effective and easy to use. In other words, BPNN method is capable to producing good value of forecasting.
\end{abstract}

Keywords - BPNN; foreign tourists; BPS; MSE

Abstrak - Pemanfaatan backpropagation neural network (BPNN) dengan data deret waktu telah digunakan dalam paper ini. Metode BPNN telah digunakan untuk memprediksi data kedatangan turis asing ke Indonesia, dimana data turis tersebut diambil dari badan pusat statistik Indonesia (BPS). Hasil pengujian menunjukkan bahwa metode BPNN dengan dua lapisan tersembunyi mampu memodelkan dan meramalkan data kedatangan turis asing ke Indonesia yang diindikasikan dengan nilai mean square error (MSE). Penelitian ini merekomendasikan bahwa metode BPNN mampu menjadi alternative metode dalam memprediksi data yang berjenis deret waktu karena metode BPNN efektif dan lebih mudah digunakan serta mampu menghasilkan akurasi nilai peramalan yang baik.

Kata Kunci - BPNN; turis asing; BPS; MSE

\section{Pendahuluan}

Hingga saat ini, metode statistik untuk peramalan masih banyak digunakan seperti simple regression analysis (SRA), decomposition, exponential smoothing (ES), autoregressive integrated moving average (ARIMA) dan seasonal autoregressive integrated moving average (SARIMA) [1-3]. Namun demikian

*) Penulis Korespondensi (Haviluddin)

Email: haviluddin@unmul.ac.id metode statistik tersebut memiliki beberapa kelemahan seperti tingkat akurasi yang dihasilkan kurang baik dan data yang digunakan untuk peramalan harus bersifat linear [4-7].

Untuk mengatasi kelemahan dalam metode statistik, para peneliti banyak menerapkan metode jaringan syaraf tiruan (JST) dengan berbagai algoritma pelatihan untuk mendapatkan hasil peramalan yang lebih baik [8-14]. Selain itu metode JST ini sangat baik digunakan pada data deret waktu yang bersifat tidak linear (nonlinear) [4, 15-18]. Penelitian terbaru menyebutkan bahwa metode jaringan syaraf tiruan (JST) sangat baik dalam meramalkan turis di Mozambique (Januari 2004-Desember 2013). Model akurasi JST terbaik dinyatakan dengan MSE [19]. Hal ini menegaskan bahwa metode jaringan syaraf tiruan (JST) masih relevan untuk digunakan [20].

Oleh karena itu, dalam penelitian ini metode backpropagation neural network (BPNN) dipilih untuk meramalkan data kedatangan turis asing ke Indonesia. Penelitian ini akan dilakukan dengan mengeksplorasi parameter BPNN seperti laju pembelajaran (learning rate) dan arsitektur jaringan.

Lebih lanjut, hasil penelitian ini diharapkan dapat membantu memberikan informasi bagi para pengambil keputusan untuk lebih menarik turis asing datang ke Indonesia, mengantisipasi kenyamanan turis asing saat berada di Indonesia dan lain sebagainya. Paper ini terdiri dari empat bagian. Bagian pertama adalah motivasi penelitian ini. Bagian kedua adalah menjelaskan metodologi dan teknik yang digunakan. Bagian ketiga adalah menerangkan hasil pengujian dengan metode dan data yang telah ditetapkan. Dan, bagian terakhir adalah kesimpulan dan saran yang diperoleh setelah pengujian, serta rencana penelitian selanjutnya.

\section{Metodologi}

Pada bagian ini, akan dijelaskan secara singkat deret waktu, metode BPNN dan pengukuran hasil simulasi peramalan yang digunakan dalam penelitian ini.

\section{Data Deret Waktu}

Deret waktu adalah jenis kumpulan data yang terurut dalam waktu dan bersifat historikal. Secara prinsip, data deret waktu digunakan untuk memprediksi masa depan menggunakan data $\left(\mathrm{y}_{\mathrm{t}+1}, \mathrm{y}_{\mathrm{t}+2}, \ldots, \mathrm{y}_{\mathrm{t}+\mathrm{n}}\right)$ 
berdasarkan data deret waktu sebelumnya $\left(\mathrm{x}_{\mathrm{t}+1}, \mathrm{x}_{\mathrm{t}+2}, \ldots\right.$, $\mathrm{x}_{\mathrm{t}+\mathrm{n}}$ ) [21]. Dalam penelitian ini, data kedatangan turis asing ke Indonesia dari tahun 1974-2013 (40 tahun), yang diambil dari website Badan Pusat Statistik Indonesia (BPS) http://www.bps.go.id. Data tersebut dapat dilihat pada Tabel 1 dan diplotkan pada Gambar 1. Adapun software modeling analisa data yang digunakan dalam penelitian ini adalah MATLAB R2013b.

Tabel 1. Data Deret Waktu Kedatangan Turis Asing ke Indonesia Pada Tahun 1974-2013

\begin{tabular}{ccccc}
\hline $\mathbf{1 9 7 4}$ & $\mathbf{1 9 7 5}$ & $\mathbf{1 9 7 6}$ & $\mathbf{1 9 7 7}$ & $\mathbf{1 9 7 8}$ \\
\hline 313.452 & 366.293 & 401.237 & 433.393 & 468.614 \\
\hline $\mathbf{1 9 7 9}$ & $\mathbf{1 9 8 0}$ & $\mathbf{1 9 8 1}$ & $\mathbf{1 9 8 2}$ & $\mathbf{1 9 8 3}$ \\
\hline 501.430 & 561.178 & 600.151 & 592.046 & 638.855 \\
\hline $\mathbf{1 9 8 4}$ & $\mathbf{1 9 8 5}$ & $\mathbf{1 9 8 6}$ & $\mathbf{1 9 8 7}$ & $\mathbf{1 9 8 8}$ \\
\hline 700.910 & 749.351 & 825.035 & 1.060 .347 & 1.301 .049 \\
\hline $\mathbf{1 9 8 9}$ & $\mathbf{1 9 9 0}$ & $\mathbf{1 9 9 1}$ & $\mathbf{1 9 9 2}$ & $\mathbf{1 9 9 3}$ \\
\hline 1.625 .965 & 2.177 .566 & 2.569 .870 & 3.064 .161 & 3.403 .138 \\
\hline $\mathbf{1 9 9 4}$ & $\mathbf{1 9 9 5}$ & $\mathbf{1 9 9 6}$ & $\mathbf{1 9 9 7}$ & $\mathbf{1 9 9 8}$ \\
\hline 4.006 .312 & 4.324 .229 & 5.034 .472 & 5.185 .243 & 4.606 .416 \\
\hline $\mathbf{1 9 9 9}$ & $\mathbf{2 0 0 0}$ & $\mathbf{2 0 0 1}$ & $\mathbf{2 0 0 2}$ & $\mathbf{2 0 0 3}$ \\
\hline 4.727 .520 & 5.064 .217 & 5.153 .620 & 5.033 .400 & 4.467 .021 \\
\hline $\mathbf{2 0 0 4}$ & $\mathbf{2 0 0 5}$ & $\mathbf{2 0 0 6}$ & $\mathbf{2 0 0 7}$ & $\mathbf{2 0 0 8}$ \\
\hline 5.321 .165 & 5.002 .101 & 4.871 .351 & 5.505 .759 & 6.234 .497 \\
\hline $\mathbf{2 0 0 9}$ & $\mathbf{2 0 1 0}$ & $\mathbf{2 0 1 1}$ & $\mathbf{2 0 1 2}$ & $\mathbf{2 0 1 3}$ \\
\hline 6.323 .730 & 7.002 .944 & 7.649 .731 & 8.044 .462 & 8.802 .129 \\
\hline & & & &
\end{tabular}

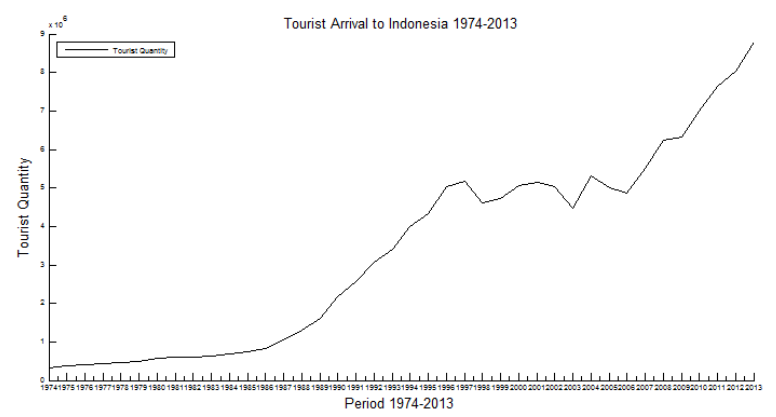

Gambar 1. Plot Data Kedatangan Turis Asing ke Indonesia Pada Tahun 1974-2013

Sebelum proses peramalan dilakukan, maka proses normalisasi data deret waktu sebaiknya dilakukan dengan menggunakan metode statistik. Hal ini bertujuan untuk mempercepat proses pelatihan JST tanpa mengurangi nilai data sebenarnya [21, 22]. Dalam penelitian ini, data deret waktu dinormalisasi dalam ordo $[0,1]$ dengan menggunakan rumus sebagai berikut.

$$
\bar{x}=\frac{\left(x-x_{\min }\right)}{\left(x_{\max }-x_{\min }\right)}
$$

dimana, $\bar{x}$ adalah nilai data deret waktu normalisasi dari $x ;{ }^{x}$ adalah nilai data deret waktu asli; $x_{\max }$ adalah nilai maksimum data deret waktu, and $x_{\min }$ adalah nilai minimum data deret waktu. Kemudian, untuk mengembalikan ke data asli maka dilakukan proses denormalization. Adapun data hasil normalisasi seperti pada Tabel 2 .

Tabel 2. Data Deret Waktu Kedatangan Turis Asing ke Indonesia Pada Tahun 1974-2013 Setelah Normalisasi

\begin{tabular}{|c|c|c|c|c|c|c|c|}
\hline \multirow[t]{2}{*}{ Group } & \multicolumn{6}{|c|}{$\begin{array}{c}\text { Input Neurons } \\
\mathrm{P}=[\mathrm{p}(\mathrm{t}-5), \mathrm{p}(\mathrm{t}-4), \mathrm{p}(\mathrm{t}-3), \mathrm{p}(\mathrm{t}-2), \mathrm{p}(\mathrm{t}-1)]\end{array}$} & \multirow{2}{*}{$\begin{array}{c}\text { Output } \\
\text { Neurons } \\
\mathrm{T}\end{array}$} \\
\hline & & $t-5)$ & $\mathrm{p}(\mathrm{t}-4)$ & $\mathrm{p}(\mathrm{t}-3)$ & $\mathrm{p}(\mathrm{t}-2)$ & $\mathrm{p}(\mathrm{t}-1)$ & \\
\hline \multirow{30}{*}{ Training } & 1 & 0.000 & 0.006 & 0.010 & 0.014 & 0.018 & 0.022 \\
\hline & 2 & 0.006 & 0.010 & 0.014 & 0.018 & 0.022 & 0.029 \\
\hline & 3 & 0.010 & 0.014 & 0.018 & 0.022 & 0.029 & 0.034 \\
\hline & 4 & 0.014 & 0.018 & 0.022 & 0.029 & 0.034 & 0.033 \\
\hline & 5 & 0.018 & 0.022 & 0.029 & 0.034 & 0.033 & 0.038 \\
\hline & 6 & 0.022 & 0.029 & 0.034 & 0.033 & 0.038 & 0.046 \\
\hline & 7 & 0.029 & 0.034 & 0.033 & 0.038 & 0.046 & 0.051 \\
\hline & 8 & 0.034 & 0.033 & 0.038 & 0.046 & 0.051 & 0.060 \\
\hline & 9 & 0.033 & 0.038 & 0.046 & 0.051 & 0.060 & 0.088 \\
\hline & 10 & 0.038 & 0.046 & 0.051 & 0.060 & 0.088 & 0.116 \\
\hline & 11 & 0.046 & 0.051 & 0.060 & 0.088 & 0.116 & 0.155 \\
\hline & 12 & 0.051 & 0.060 & 0.088 & 0.116 & 0.155 & 0.220 \\
\hline & 13 & 0.060 & 0.088 & 0.116 & 0.155 & 0.220 & 0.266 \\
\hline & 14 & 0.088 & 0.116 & 0.155 & 0.220 & 0.266 & 0.324 \\
\hline & 15 & 0.116 & 0.155 & 0.220 & 0.266 & 0.324 & 0.364 \\
\hline & 16 & 0.155 & 0.220 & 0.266 & 0.324 & 0.364 & 0.435 \\
\hline & 17 & 0.220 & 0.266 & 0.324 & 0.364 & 0.435 & 0.472 \\
\hline & 18 & 0.266 & 0.324 & 0.364 & 0.435 & 0.472 & 0.556 \\
\hline & 19 & 0.324 & 0.364 & 0.435 & 0.472 & 0.556 & 0.574 \\
\hline & 20 & 0.364 & 0.435 & 0.472 & 0.556 & 0.574 & 0.506 \\
\hline & 21 & 0.435 & 0.472 & 0.556 & 0.574 & 0.506 & 0.520 \\
\hline & 22 & 0.472 & 0.556 & 0.574 & 0.506 & 0.520 & 0.560 \\
\hline & 23 & 0.556 & 0.574 & 0.506 & 0.520 & 0.560 & 0.570 \\
\hline & 24 & 0.574 & 0.506 & 0.520 & 0.560 & 0.570 & 0.556 \\
\hline & 25 & 0.506 & 0.520 & 0.560 & 0.570 & 0.556 & 0.489 \\
\hline & 26 & 0.520 & 0.560 & 0.570 & 0.556 & 0.489 & 0.590 \\
\hline & 27 & 0.560 & 0.570 & 0.556 & 0.489 & 0.590 & 0.552 \\
\hline & 28 & 0.570 & 0.556 & 0.489 & 0.590 & 0.552 & 0.537 \\
\hline & 29 & 0.556 & 0.489 & 0.590 & 0.552 & 0.537 & 0.612 \\
\hline & 30 & 0.489 & 0.590 & 0.552 & 0.537 & 0.612 & 0.698 \\
\hline \multirow{10}{*}{ Testing } & 31 & 0.590 & 0.552 & 0.537 & 0.612 & 0.698 & 0.708 \\
\hline & 32 & 0.552 & 0.537 & 0.612 & 0.698 & 0.708 & 0.788 \\
\hline & 33 & 0.537 & 0.612 & 0.698 & 0.708 & 0.788 & 0.864 \\
\hline & 34 & 0.612 & 0.698 & 0.708 & 0.788 & 0.864 & 0.911 \\
\hline & 35 & 0.698 & 0.708 & 0.788 & 0.864 & 0.911 & 1.000 \\
\hline & 36 & 0.708 & 0.788 & 0.864 & 0.911 & 1.000 & 0.000 \\
\hline & 37 & 0.788 & 0.864 & 0.911 & 1.000 & 0.000 & 0.006 \\
\hline & 38 & 0.864 & 0.911 & 1.000 & 0.000 & 0.006 & 0.010 \\
\hline & 39 & 0.911 & 1.000 & 0.000 & 0.006 & 0.010 & 0.014 \\
\hline & 40 & 1.000 & 0.000 & 0.006 & 0.010 & 0.014 & 0.018 \\
\hline
\end{tabular}

\section{Backpropagation neural network (BPNN)}

Metode BPNN diperkenalkan oleh Paul Werbos pada tahun 1974, kemudian dikembangkan oleh David Parker pada tahun 1982. Selanjutnya, tahun 1986 dikembangkan lagi oleh Rumelhart dan McCelland. Metode BPNN banyak digunakan dalam memecahkan berbagai persoalan simulasi termasuk peramalan. 
Metode BPNN terdiri dari tiga lapisan feedforward neural network (FFNN) yaitu lapisan masukan (input layer), lapisan tersembunyi (hidden layer), dan lapisan keluaran (output layer) dengan fungsi linier [2326]. Adapun arsitektur metode BPNN seperti pada Gambar 2.

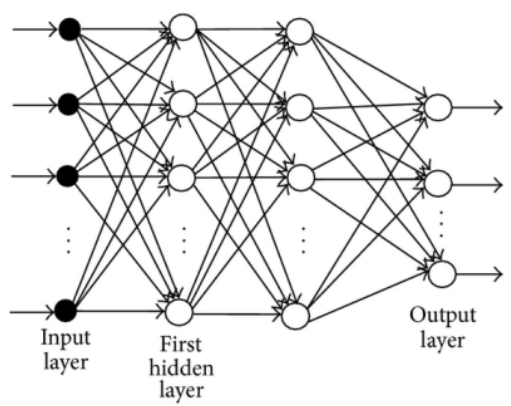

Gambar 2. Arsitektur MLP Dengan Metode BPNN

Adapun pelatihan metode BPNN sebagai berikut.

Tahap 0: Inisialisasi bobot

Tahap 1: Jika kondisi terpenuhi, lakukan tahap 2-8

Tahap 2: Untuk setiap pasangan data, lakukan tahap 3-8

\section{Fase 1: Feed forward}

Tahap 3: Setiap unit menerima signal masukan dan dikirim ke lapisan tersembunyi

Tahap 4: Hitung semua nilai dalam lapisan tersembunyi $z_{j},(j=1,2, \ldots, p)$, kemudian setiap signal input dijumlahkan dengan rumus berikut.

$\mathrm{z}_{-} n e t_{j}=v_{j 0}+\sum_{i=1}^{n} \mathrm{x}_{\mathrm{i}} v_{k j}$

Hitung fungsi aktivasi untuk menghitung signal keluaran dan dikirim ke semua unit keluaran, dengan rumus berikut.

$z_{j}=f\left(z_{-} n e t_{j}\right)=\frac{1}{1+e^{-z_{-} n e t_{j}}}$

Tahap 5: Hitung semua nilai keluaran dalam semua jaringan output $y_{k},(k=1,2, \ldots, m)$, kemudian setiap signal input dijumlahkan dengan rumus berikut.

$y_{-} n e t_{k}=w_{k o}+\sum_{j=1}^{p} \mathrm{z}_{\mathrm{j}} w_{k j}$

Hitung fungsi aktivasi untuk menghitung signal keluaran dan dikirim ke semua unit keluaran dengan rumus berikut.

$y_{k}=f\left(y_{-} n e t_{k}\right)=\frac{1}{1+e^{-y_{-} n e t_{k}}}$
Fase 2: Back propagation

Tahap 6: Hitung faktor $\delta$ unit keluaran berdasarkan error $y_{k},(k=1,2, \ldots, m)$

$\delta_{k}=\left(\mathrm{t}_{k}-\mathrm{y}_{k}\right) f^{\prime}\left(\mathrm{y}-\right.$ net $\left._{k}\right)=\left(\mathrm{t}_{k}-\mathrm{y}_{k}\right) \mathrm{y}_{k}\left(1-\mathrm{y}_{k}\right)$

dimana,

$\mathrm{t}_{k}=$ target keluaran

$\delta=$ unit keluaran yang digunakan untuk memperbaharui bobot

Hitung perubahan bobot baru dan bias $\mathrm{w}_{k j}$, dengan nilai laju pembelajaran $\alpha$,

$\delta_{w j i}=\alpha \delta_{k}, z_{j}(k=1,2, \ldots, m ; j=0,1, \ldots, p)$

Tahap 7: Hitung faktor $\delta$ dalam unit lapisan tersembunyi berdasarkan nilai error $z_{j}(j=1,2, \ldots, p)$

$\delta_{-} n e t_{j}=\sum_{k=1}^{m} \delta_{\mathrm{k}} w_{k j}$

Hitung faktor $\delta$ pada lapisan tersembunyi

$\delta_{j}=\delta_{\text {net }_{j}} f^{\prime}\left(z_{\text {net }_{j}}\right)=\delta_{\text {net }_{j}}, z_{j}\left(1-z_{j}\right)$

Hitung nilai perubahan bobot dan bias $v_{j i}$

$\left.\delta \mathrm{y}_{j i}=\alpha \delta_{k}, z_{j}, k=1,2, \ldots, p ; j=0,1, \ldots, n\right)$

Fase 3: Modifikasi bobot

Tahap 8: Hitung semua perubahan bobot dan bias yang mengarah ke unit keluaran

$\mathrm{w}_{k j(\text { new })}=\mathrm{w}_{k j \text { (old })}+\delta \mathrm{w}_{j i}$;

$(k=1,2, \ldots, p ; j=0,1, \ldots, n)$

Hitung perubahan bobot dan bias di dalam lapisan tersembunyi dengan rumus berikut.

$\mathrm{v}_{k j(\text { new })}=\mathrm{v}_{k j(\text { old })}+\delta \mathrm{v}_{j i} ;$

$(j=1,2, \ldots, p ; w=0,1, \ldots, n)$

\section{Pengukuran hasil simulasi}

Terdapat beberapa metode dalam statistik untuk melakukan pengukuran suatu model peramalan seperti mean absolute error (MAE), mean square error (MSE), root mean squared error (RMSE), dan normalize mean square error (NMSE). Pengukuran metode peramalan bertujuan untuk mendapatkan nilai terbaik antara nilai asli dan nilai hasil peramalan [27, 28]. Dalam penelitian 
ini, metode MSE dipilih untuk mengukur akurasi peramalan. Adapun rumus MSE sebagai berikut.

$$
M S E=\frac{1}{M} \sum_{t=1}^{M}\left(x_{t}-\hat{x}_{i}\right)^{2}
$$

dimana, $x_{t}$ adalah nilai observasi data; $x_{t}-\hat{x}_{i}$ adalah nilai hasil peramalan; $M$ adalah nilai dari deret waktu.

\section{Hasil dan Pembahasan}

Bagian ini adalah menerangkan hasil pengujian metode BPNN yang diujikan pada data kedatangan turis asing ke Indonesia. Berdasarkan aturan pelatihan dalam JST, data kedatangan turis ke Indonesia sebanyak 40 sampel dibagi menjadi dua bagian; data pelatihan sebanyak 30 sampel dan data pengujian sebanyak 10 . Adapun jumlah masukan yang digunakan sebanyak lima neurons $\mathrm{P}=[\mathrm{p}(\mathrm{t}-5), \mathrm{p}(\mathrm{t}-4), \mathrm{p}(\mathrm{t}-3), \mathrm{p}(\mathrm{t}-2), \mathrm{p}(\mathrm{t}-1)]$, dan jumlah keluaran sebanyak satu neuron [Output Neurons T]. Data masukan dalam dilihat pada Tabel 2.

Dalam eksperimen ini, arsitektur metode BPNN yang digunakan terdiri dari dua kategori, yaitu satu lapisan tersembunyi dan dua lapisan tersembunyi. Sedangkan fungsi aktivasi yang digunakan; untuk satu lapisan tersembunyi; dari lapisan masukan ke lapisan tersembunyi adalah tansig, dan dari lapisan tersembunyi ke lapisan keluaran adalah purelin. Untuk dua lapisan tersembunyi; dari lapisan masukan ke lapisan tersembunyi adalah tansig dan logsig, dan dari lapisan tersembunyi ke lapisan keluaran adalah purelin. Sedangkan algoritma pelatihan yang digunakan untuk semua arsitektur metode BPNN adalah gradient descent (traingdm). Dalam pengujian ini, metode statistik MSE digunakan untuk membandingkan nilai asli dan nilai hasil peramalan. Nilai MSE yang mendekati 1 merupakan nilai hasil pelatihan metode BPNN dengan arsitektur yang terbaik.

Dari hasil pelatihan bahwa metode BPNN dengan arsitektur satu lapisan tersembunyi terlihat memiliki nilai MSE yang cukup baik dan konstan. Sedangkan, hasil pelatihan metode BPNN dengan arsitektur dua lapisan tersembunyi terlihat nilai MSE bervariasi. Dimana nilai MSE kedua arsitektur tersebut diperoleh dari hasil pelatihan metode BPNN yang dilakukan saat satu kali pelatihan dan hasil pelatihan dihentikan setelah mencapai epoch 100 .

Adapun, nilai MSE dari metode BPNN satu lapisan tersembunyi dilakukan komparasi dengan dua lapisan tersembunyi. Hal ini dilakukan untuk melihat performansi secara keseluruhan dari arsitektur metode BPNN. Dengan kata lain, nilai MSE yang mendekati 1, mencerminkan bahwa metode BPNN dengan arsitektur terbaik. Adapun, komparasi nilai MSE pada metode BPNN dengan beberapa arsitektur dapat dilihat dalam Tabel 3 dan 4.
Dalam eksperimen ini, arsitektur 5-10-10-1 merupakan simulasi arsitektur metode BPNN terbaik dalam meramalkan kedatangan turis asing ke Indonesia yang dibandingkan dengan data target [Output Neurons T]. Hal ini ditandai dengan nilai MSE yang dihasilkan mendekati 1 yaitu 0.00071571 , dengan performansi pelatihan yaitu 0.020676. Simulasi hasil peramalan dapat dilihat pada Tabel 5.

Tabel 3. Hasil Pengujian Metode BPNN Dengan Arsitektur Satu Lapisan Tersembunyi

\begin{tabular}{ccccc}
\hline $\begin{array}{c}\text { Arsitektur } \\
\text { Metode BPNN }\end{array}$ & Epoch & LR & Momentum & MSE \\
\hline $5-10-1$ & 100 & 0.1 & 0.8 & 0.00178099 \\
$5-20-1$ & 100 & 0.1 & 0.8 & 0.00103908 \\
$5-30-1$ & 100 & 0.1 & 0.8 & 0.00204248 \\
$5-40-1$ & 100 & 0.1 & 0.8 & 0.00319081 \\
$5-50-1$ & 100 & 0.1 & 0.8 & 0.00608444 \\
\hline
\end{tabular}

Tabel 4. Hasil Pengujian Metode BPNN Dengan Arsitektur Dua Lapisan Tersembunyi

\begin{tabular}{ccccc}
\hline $\begin{array}{c}\text { Arsitektur } \\
\text { Metode BPNN }\end{array}$ & Epoch & LR & Momentum & MSE \\
\hline $5-10-10-1$ & 100 & 0.1 & 0.8 & $0.00071571 *$ \\
$5-20-10-1$ & 100 & 0.1 & 0.8 & 0.00127176 \\
$5-30-10-1$ & 100 & 0.1 & 0.8 & 0.00178015 \\
$5-40-10-1$ & 100 & 0.1 & 0.8 & 0.00138973 \\
$5-50-10-1$ & 100 & 0.1 & 0.8 & 0.00116487 \\
\hline
\end{tabular}

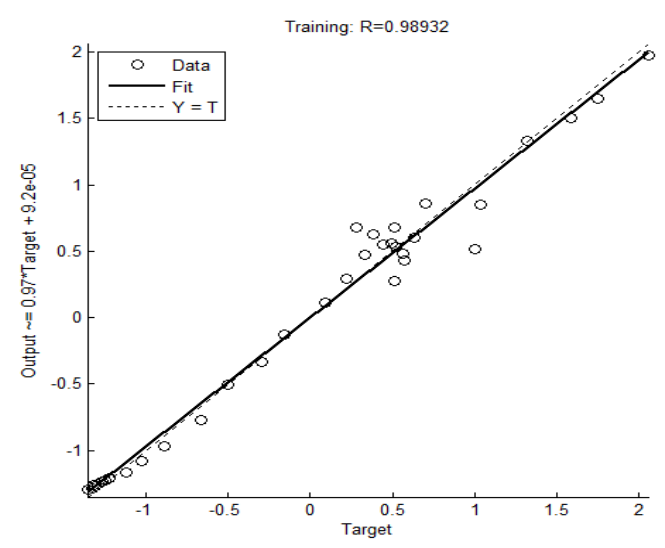

Gambar 3. Regresi Metode BPNN Dengan Arsitektur 510-10-1 


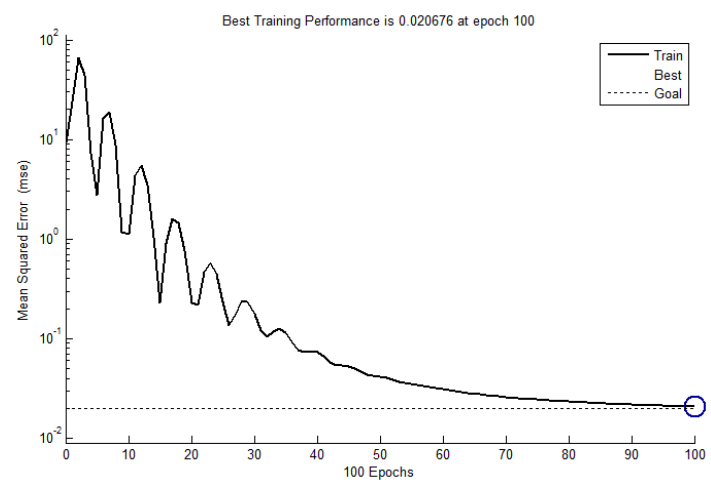

Gambar 4. Performance Metode BPNN Dengan Arsitektur 5-10-10-1

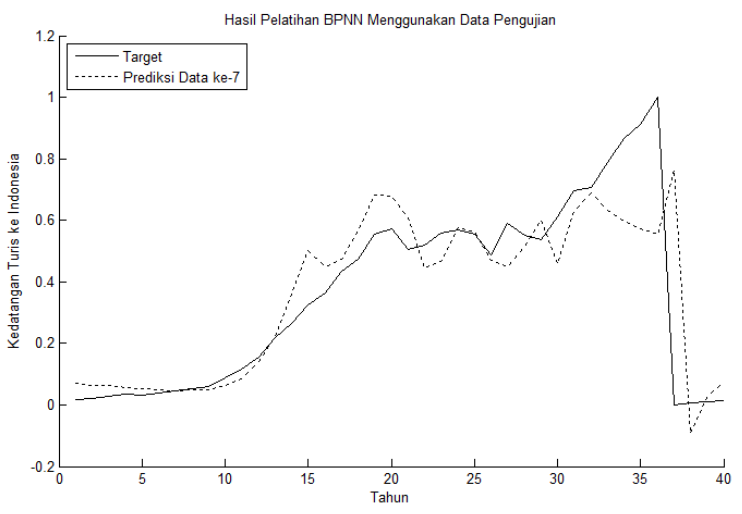

Gambar 5. Hasil Pelatihan Metode BPNN Dengan Arsitektur 5-10-10-1

Tabel 5. Perbandingan Data Target [Output Neurons T] dan Data Hasil Prediksi

\begin{tabular}{ccc}
\hline Output Neurons T & Prediksi & Error Prediksi \\
\hline 0.708 & 0.6306 & -0.0774 \\
0.788 & 0.6889 & -0.0991 \\
0.864 & 0.6321 & -0.2319 \\
0.911 & 0.5976 & -0.3134 \\
1.000 & 0.5740 & -0.426 \\
0.000 & 0.5535 & 0.5535 \\
0.006 & 0.7621 & 0.7561 \\
0.010 & -0.0924 & -0.1024 \\
0.014 & 0.0244 & 0.0104 \\
0.018 & 0.0761 & -0.0774 \\
\hline
\end{tabular}

\section{KESIMPULAN DAN SARAN}

Paper ini mempresentasikan penerapan metode BPNN dalam melakukan peramalan data deret waktu. Data yang digunakan dalam penelitian ini adalah data kedatangan turis asing ke Indonesia. Pelatihan dilakukan dengan menggunakan dua jenis arsitektur BPNN: satu lapisan tersembunyi dan dua lapisan tersembunyi. Mean square error (MSE) digunakan untuk melihat performansi dari setiap arsitektur BPNN. Dari pengujian yang dilakukan terlihat bahwa metode BPNN dapat digunakan sebagai alat bantu simulasi dalam peramalan.
Perbandingan metode dalam JST, optimalisasi metode BPNN menggunakan algoritma seperti algoritma genetika (GA), particle swarm optimization (PSO) merupakan rencana penelitian ke depan.

\section{Daftar Pustaka}

[1]. H. Hassani, A. Webster, E. S. Silva, and S. Heravi, "Forecasting U.S. Tourist arrivals using optimal Singular Spectrum Analysis," Tourism Management, vol. 46 (2015), pp. 322-335, 2015.

[2]. X. Sun, W. Sun, J. Wang, Y. Zhang, and Y. Gao, "Using a GreyeMarkov model optimized by Cuckoo search algorithm to forecast the annual foreign tourist arrivals to China," Tourism Management, vol. 52 (2016), pp. 369-379, 2016.

[3]. W. Lijuan and C. Guohua, "Seasonal SVR with FOA algorithm for single-step and multi-step ahead forecasting in monthly inbound tourist flow," Knowledge-Based Systems, vol. 110 (2016), pp. 157-166, 2016

[4]. O. Claveria and S. Torra, "Forecasting tourism demand to Catalonia: Neural networks vs. time series models," Economic Modelling, vol. 36, pp. 220-228, 2014.

[5]. Haviluddin and R. Alfred, "Forecasting Network Activities Using ARIMA Method," Journal of Advances in Computer Networks (JACN), vol. 2, (3) September 2014, pp. 173-179, 2014.

[6]. M. C. Altunel and B. Erkut, "Cultural tourism in Istanbul: The mediation effect of tourist experience and satisfaction on the relationship between involvement and recommendation intention," Journal of Destination Marketing \& Management, vol. 4 (2015), pp. 213-221, 2015.

[7]. C.-W. Wu, "Foreign tourists' intentions in visiting leisure farms," Journal of Business Research, vol. 68 (2015), pp. $757-$ 762, 2015.

[8]. B. Majhi, M. Rout, and V. Baghel, "On the development and performance evaluation of a multiobjective GA-based RBF adaptive model for the prediction of stock indices," Journal of King Saud University - Computer and Information Sciences, pp. xx-xx, 2014.

[9]. Purnawansyah and Haviluddin, "Comparing performance of Backpropagation and RBF neural network models for predicting daily network traffic," in The $4^{\text {th }}$ MICEEI (Makassar International Conference on Electrical Engineering and Informatics), Makassar City, South Sulawesi Province, Indonesia, 2014, pp. 166-169.

[10]. Y.-H. Liang, "Forecasting models for Taiwanese tourism demand after allowance for Mainland China tourists visiting Taiwan," Computers \& Industrial Engineering, vol. 74 (2014), pp. 111-119, 2014.

[11]. J. P. Teixeira and P. O. Fernandes, "Tourism time series forecast with artificial neural networks," TÉKHNE - Review of Applied Management Studies, vol. (2014) 12, pp. 26-36, 2014.

[12]. J. P. Teixeira and P. O. Fernandes, "Tourism Time Series Forecast - Different ANN Architectures with Time Index Input," Procedia Technology, vol. 5, pp. 445 - 454, 2012.

[13]. E. Ma, Y. Liu, J. Li, and S. Chen, "Anticipating Chinese tourists arrivals in Australia: A time series analysis," Tourism Management Perspectives, vol. 17 (2016), pp. 50-58, 2016.

[14]. P. Chaitip and C. Chaiboonsri, "International Tourists Arrival to Thailand: Forecasting by Non-Linear Model," in International Conference on Applied Economics (ICOAE) 2014, 2014, pp. $100-109$.

[15]. G. Chen, K. Fu, Z. Liang, T. Sema, C. Li, P. Tontiwachwuthikul, and R. Idem, "The genetic algorithm based back propagation neural network for MMP prediction in $\mathrm{CO}_{2}$ EOR process," Fuel, vol. 126, (2014), pp. 202-212, 2014.

[16]. A. U. Haque, P. Mandal, M. E. Kaye, J. Meng, L. Chang, and T. Senjyu, "A new strategy for predicting short-term wind speed 
using soft computing models," Renewable and Sustainable Energy Reviews, vol. 16, (2012), pp. 4563-4573, 2012.

[17]. Y. Birdi, T. Aurora, and P. Arora, "Study of Artificial Neural Networks and Neural Implants," International Journal on Recent and Innovation Trends in Computing and Communication, vol. 1, (4), pp. 258 - 262, 2013.

[18]. G. Stalidis, D. Karapistolis, and A. Vafeiadis, "Marketing decision support using Artificial Intelligence and Knowledge Modeling: application to tourist destination management," in International Conference on Strategic Innovative Marketing, IC-SIM 2014, September 1-4, 2014,, Madrid, Spain, 2015, pp. $106-113$.

[19]. H. A. Constantino, P. O. Fernandes, and J. P. Teixeira, "Tourism demand modelling and forecasting with artificial neural network models: The Mozambique case study," TÉKHNE - Review of Applied Management Studies, vol. (2016) xxx, pp. xxx---xxx, 2016.

[20]. O. Claveria, E. Monte, and S. Torra, "Common trends in international tourism demand: Are they useful to improve tourism predictions?," Tourism Management Perspectives, vol. 16 (2015), pp. 116-122, 2015.

[21]. G. E. P. Box, G. M. Jenkins, and G. C. Reinsel. (2008). Time Series Analysis Forecasting and Control $4^{\text {th }}$ Edition.

[22]. M. Melanie. (1996). An Introduction to Genetic Algorithms.

[23]. K. G. Upadhyay, A. K. Choudhary, and M. M. Tripathi, "Short- term wind speed forecasting using feed-forward backpropagation neural network," International Journal of Engineering, Science and Technology, vol. 3, No. 5, pp. 107$112,2011$.

[24]. H. H. Örkcü and H. Bal, "Comparing performances of backpropagation and genetic algorithms in the data classification," Expert Systems with Applications, vol. 38, (2011), pp. 3703-3709, 2011.

[25]. I. A. Basheer and M. Hajmeer, "Artificial neural networks: fundamentals, computing, design, and application," Journal of Microbiological Methods, vol. 43, pp. 3-31, 2000.

[26]. G. Sermpinis, C. Dunis, J. Laws, and C. Stasinakis, "Forecasting and trading the EUR/USD exchange rate with stochastic Neural Network combination and time-varying leverage," Decision Support Systems, vol. 54, (2012), pp. 316$329,2012$.

[27]. H.-X. Huang, J.-C. Li, and C.-L. Xiao, "A proposed iteration optimization approach integrating backpropagation neural network with genetic algorithm," Expert Systems with Applications, vol. 42, pp. 146-155, 2015.

[28]. Haviluddin, R. Alfred, J. H. Obit, M. H. A. Hijazi, and A. A. A. Ibrahim, "A Performance Comparison of Statistical and Machine Learning Techniques in Learning Time Series Data," Advanced Science Letters, pp. 3037-3041, 2015. 